Ігор Анатолійович Пількевич (доктор техн. наук, професор) ${ }^{1}$

Юрій Борисович Бродський (канд. техн. наук, доцент) $)^{2}$

Олександр Володимирович Маєвський (канд. техн. наук)

'Житомирський військовий інститут, Житомир, Украӥна

${ }^{2}$ Житомирський національний агроекологічний університет, Житомир, Украӥна

${ }^{3}$ Житомирський державний технологічний університет, Житомир, Украӥна

\title{
МОДЕЛЮВАННЯ ВПЛИВУ ШУМІВ НА КУБІТОВІ ТА БІТОВІ СИГНАЛИ
}

\begin{abstract}
Причиною виникнення ідеї квантових обчислень $\epsilon$ принщипова обмеженість «класичних» комп'ютерів розв'язувати певний клас задач з необхідністю залучення «експоненціально» великих обчислювальних ресурсів. Реальні квантові системи схильні до впливу зовнішнього середовища, щцо $\epsilon$ вагомою перешкодою при створенні квантових комп'ютерів. В статті пропонується один з підходів до оцінювання зовнішніх впливів в рамках вирішення проблеми збереження достовірної інформації в квантових системах шляхом моделювання впливу шуму на кубітові та бітові сигнали з використанням ергодичних ланщңюгів Маркова. Показано, щчо в ситуащіі стороннього впливу «щуму» розподіленого за експоненціальним законом квантова система переходить в нестабільний стан.
\end{abstract}

Ключові слова: квантові обчислення, сторонній вплив, кубітові сигнали, ергодичні ланцюги Маркова.

\section{Вступ}

Область знань про квантові обчислення знаходиться на стику квантової механіки, сучасної математичної фізики, класичної теорії інформації та комп’ютерних наук. Сама ідея квантових обрахунків належить математику Ю. Маніну (1980), однак ii активне обговорення та спроби реалізації виникли після публікації статті [1] відомого американського фізика Р. Фейнмана (1982), де він висловив можливість використання квантової системи для розв'язання складних обчислювальних задач (в тому числі моделювання квантової механіки) 3 необхідністю залучення «експоненціально великих» комп'ютерних ресурсів. Фейнман висунув ідею створення принципово нового комп'ютера на основі квантових ефектів суперпозиції та заплутаності.

Перші формальні моделі універсального квантового комп'ютера П. Беньоффа (1982) та Д. Дойча (1985), а також перший квантовий алгоритм П. Шора (1994) надали реальний поштовх розвитку квантової теорії інформації та квантових обчислень.

Подальший розвиток квантової теорії дозволить завершити дослідження пов'язані 3 квантовими комп'ютерами. Зокрема, застосування положень квантової механіки, відкривають нові горизонти в області криптографії [2].

Системи подібного класу знаходяться в стадії розробки.

Постановка проблеми. Квантова система в реальності завжди контактує із зовнішнім середовищем, оскільки повністю ізолювати іiї неможливо. Відповідно, квантова інформація, яка передається в системі може бути не тільки пошкодженою, а й повністю знищеною. Квантовий канал зв'язку можна зруйнувати, але неможливо розкрити (Д. Дойч, П. Шор). Тому, зовнішні впливи приводять до порушення квантового стану i такі особливості та переваги квантових обчислень як паралелізм та, особливо, заплутаність станів сукупності кубіт, що $\epsilon$ необхідною умовою квантового прискорення, стають перешкодою при створенні квантових комп'ютерів.

Таким чином, виникає проблема збереження достовірності переносимої інформації в квантових системах і для піi вирішення необхідно вивчити механізми зовнішнього впливу [3], або впливу «шумів», враховуючи їх закони розподілу та фізичну природу.

Аналіз останніх досліджень і публікацій. В статтях присвячених кубітовим системам [4] висвітлено властивості кубітів, квантових регістрів, розкрито ідею «сплетених» станів. Описано дії логічних операторів [5] та описано «паралелізм» обчислень. Наведено ефективні схеми зчитування та запису інформації в кубіти. Розкрито механізми взаємодії з електромагнітними полями. Висвітлено питання об'єднання сотень надпровідникових кубітів в єдину систему. При цьому в зазначених дослідженнях не зазначено ефекти від «шумових» факторів.

Мета статті. $\epsilon$ моделювання стану $\psi-$ функції кубітів 3 урахуванням впливу «шуму» розподіленого за експоненціальним законом.

Виклад основного матеріалу дослідження

(C) І.А. Пількевич, Ю.Б. Бродський, О.В. Маєвський 
Хвильові функції кубіта у двох основних станах позначають як $\psi(|0\rangle)$ та $\psi(|1\rangle)$ на сфері Блоха (рис.1). Кубіт може знаходитись в багатьох інших станах, які описуються хвильовою функцією. Такі стани називають змішаними або гібридними.

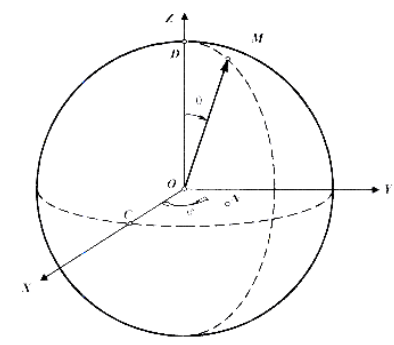

Рис.1. Сфера Блоха. Можливі стани кубіта Запишемо суперпозицію хвильової функції:

$$
\psi=A \psi(|1\rangle)+B \psi(|0\rangle) .
$$

Для різних станів кубіта ставиться у відповідність хвильова функція

$$
\psi=\psi(|1\rangle) \operatorname{Cos} \theta+e^{i \varphi} \psi(|0\rangle) \operatorname{Sin} \theta .
$$

При зчитуванні стану кубіта взаємодія 3 пристроєм змінює ситуацію. Якщо пристрій зчитування є класично бістабільним, тобто може зчитати лише «0» або «1». Будь який інший стан, в якому знаходиться кубіт перед зчитуванням, визначає лише ймовірності зчитування «0» та «1».

$$
\mathrm{P}(1)=\mathrm{a}^{2} ; \quad \mathrm{P}(0)=1-\mathrm{a}^{2} .
$$

За принципом суперпозиції, квантовий регістр 3 n кубітів може перебувати і в багатьох інших «змішаних станах», які описуються хвильовими функціями, що $є$ лінійними комбінаціями «базисних»:

$$
\left.\psi=\sum_{|00.0\rangle}^{|11.1\rangle} A_{i} \psi(i\rangle\right) .
$$

Пропонується підхід для моделювання зовнішнього впливу на стан квантового регістру (для прикладу $\mathrm{n}=2$ ) $3 \quad$ використанням безперервних ланцюгів Маркова. Вважаємо для визначеності, що потік стороннього впливу розподілено за експоненційним законом:

$$
P_{i}(\tau)=e^{-\sum_{j}^{n} \omega_{i j} \tau},
$$

де $\tau$ - інтервал часу до наступлення події. Сумування йде по індексу $\mathrm{j}$; тобто при фіксованому рядку матриці переходів, отримаємо повну групу подій:

$$
\tau=-\frac{\ln \left(P_{i}(\tau)\right)}{\sum_{j=1}^{n} \omega_{i j}} ; i \neq j .
$$

Ймовірність переходу в кожен $3 \mathrm{n}$ станів визначається як:

$$
\mathrm{p}_{\mathrm{ij}}=\frac{\omega_{\mathrm{ij}}}{\sum_{\mathrm{j}=1}^{\mathrm{n}} \omega_{\mathrm{ij}}} ; \mathrm{i} \neq \mathrm{j} .
$$

Для моделювання роботи такої квантової системи, пропонується використовувати відомий метод «розіграшу по жребію». Суть методу полягає в перевірці наступних нерівностей:

$$
\sum_{i=0}^{k-1} P\left(A_{i}\right) \leq \theta_{i} \leq \sum_{i=0}^{k} P\left(A_{i}\right) .
$$

Виконання j-ї нерівності, еквівалентно появі події $\mathrm{A}_{\mathrm{j}}$.

Імітація роботи системи. Припустимо, що ланцюг Маркова представлений наступною послідовністю станів (ймовірність $\mathrm{w}_{0}$ вважається відомою, для імітації роботи системи генерується):

$\mathrm{S}_{0} \mathrm{~S}_{0} \mathrm{~S}_{1} \mathrm{~S}_{2} \mathrm{~S}_{3} \mathrm{~S}_{0} \mathrm{~S}_{1} \mathrm{~S}_{0} \mathrm{~S}_{1} \mathrm{~S}_{2} \mathrm{~S}_{0} \mathrm{~S}_{0}$.

Відповідно матриця переходів матиме вигляд:

$$
\mathrm{P}=\left\|\begin{array}{cccc}
\mathrm{w}_{0} & \mathrm{p}_{0} & 0 & 0 \\
\mathrm{w}_{1} & 0 & \mathrm{p}_{1} & 0 \\
\mathrm{w}_{2} & 0 & 0 & \mathrm{p}_{2} \\
\mathrm{w}_{3} & 0 & 0 & 0
\end{array}\right\| ;
$$

(за n кроків відповідно $\mathrm{P}^{\mathrm{n}}$ ).

Для визначеності покладемо для інтенсивностей $\mathrm{w}_{\mathrm{ij}} \rightarrow \mathrm{w} \quad \mathrm{i} \quad \mathrm{p}_{\mathrm{ij}} \rightarrow \lambda$.

$$
\lambda=300\left(\mathrm{t}^{-1}\right), \mathrm{w}=500\left(\mathrm{t}^{-1}\right),
$$

де $\mathrm{w}_{\mathrm{ij}}=\lim _{\Delta \mathrm{t} \rightarrow 0} \frac{\mathrm{w}_{\mathrm{ij}}(\mathrm{t}, \Delta \mathrm{t})}{\Delta \mathrm{t}}$ i $\quad \lambda_{\mathrm{ij}}=\lim _{\Delta \mathrm{t} \rightarrow 0} \frac{\mathrm{p}_{\mathrm{ij}}(\mathrm{t}, \Delta \mathrm{t})}{\Delta \mathrm{t}}$.

Починаємо із стану «00» (див. граф станів системи, рис. 2 ), $\mathrm{t}_{0}=0 ; \mathrm{S}_{00}$.

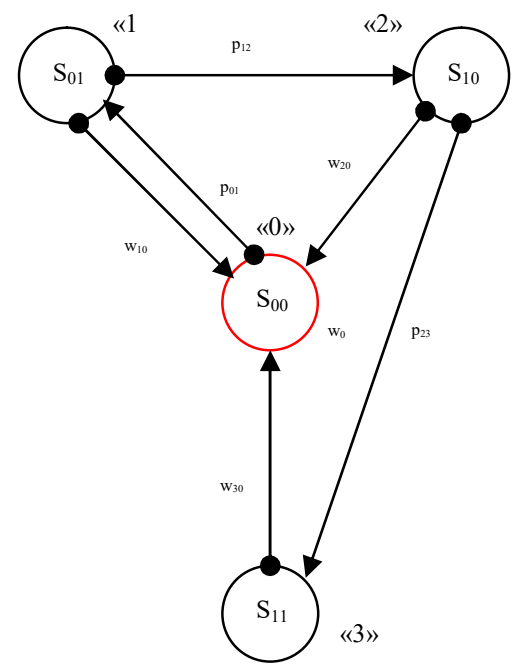

Рис.2. Граф станів системи

Визначимо час $\tau$ протягом якого система перейшла із стану «00» в стан «01». Генеруємо випадкове число $\theta$, розподілене по рівномірному закону; $\theta=0.3951$.

$$
\text { Тоді } \tau=-\frac{\ln (\theta)}{\sum_{\mathrm{j}=0}^{3} \omega_{0 j}}=-\frac{\ln (\theta)}{\lambda} \approx 3.095 \cdot 10^{-3} \mathrm{c} .
$$


Визначимо час $\tau$ протягом якого система перейшла із стану «01» в інший стан (поки що не відомий).

Генеруємо випадкове число $\theta$, розподілене по рівномірному закону; $\theta=0.9097$.

$$
\tau=-\frac{\ln (\theta)}{\sum_{\mathrm{j}=0}^{3} \omega_{1 \mathrm{j}}}=-\frac{\ln (\theta)}{\omega+\lambda} \approx 1.182 \cdot 10^{-4} \mathrm{c} .
$$

Визначимо стан, в який 3 «01» перейшла система:

ймовірність переходу в «10»

$$
\mathrm{p}_{01-10}=\frac{\lambda}{\sum_{\mathrm{j}=0}^{3} \omega_{1 \mathrm{j}}}=\frac{\lambda}{\lambda+\omega} \approx 0.375 ;
$$

ймовірність переходу в «00»

$$
\mathrm{p}_{01-00}=\frac{\omega}{\sum_{\mathrm{j}=0}^{3} \omega_{1 \mathrm{j}}}=\frac{\omega}{\lambda+\omega} \approx 0.625 .
$$

Генеруємо випадкове число $\theta$, розподілене по рівномірному закону; $\theta=0.5262 ;$ Значить система знову перейшла в стан «00» через час

$$
\mathrm{t}=3.095 \cdot 10^{-3}+1.182 \cdot 10^{-4}=3.2132 \cdot 10^{-3} \mathrm{c} .
$$

\section{Висновки й перспективи подальших досліджень}

Імітація впливу зовнішніх «шумів» на роботу квантової системи наочно демонструє нестабільність такої системи при зростанні n. Тобто зростає невизначеність при переході із стану в стан, в той же час коли бітова система 3 ймовірністю 1 переходить 3 «0» в «1» і навпаки.

Так, в статті розглянуто випадки, коли результуюча дія зовнішніх впливів призводить до ефекту зчитування i кубіт стрибкоподібно переходить в один із своїх базових станів. В загальному випадку можлива реалізація більш складної ситуації стану квантової системи в результаті зовнішнього впливу, а саме: коли вектор стану коливається в деяких межах відносно свого стану. В такому випадку пропонується вважати стан стабільним при умові не значних ймовірностей переходу в інші стани. При цьому перехідні ймовірності станів кубіта можна розраховувати в залежності від компонентів матриці оператора повороту при заданій геометрії простору (сфера Блоха).

Подальші дослідження спрямовані на ідентифікацію станів близьких до припустимих, при цьому сфера Блоха буде представлена деяким багатогранником, вершини якого представляють припустимі стани кубіта і близькі до нього.

\title{
Лimepamypa
}

1. Feynman R. Simulating physics with computers // International Journal of Theoretical Physics. - 1982.- T. 21, вип. 6-7. - С. 467 - 488. (рос. переклад: Фейнман P. Моделирование физики на компьютерах // Квантовый компьютер и квантовые вычисления (том 2). - Ижевск : РХД, 1999. - 288 с.). 2. Карлаш Г. Ю. Квантові інформаційні системи : навчальний посібник для спеціальності «Прикладна фізпка та наноматеріали» / Г. Ю. Карлаш. - К. : КНУ ім. Т. Шевченка, 2008. - 77 с. 3. Пількевич І. А., Масвський О. В. Порівняльний аналіз шумозахищеності цифрових сигналів : тези

доповіді I Всеукраїнської науково-технічної конференції «Комп'ютерні технології: інновації, проблеми, рішення» (19-20 жовтня 2018 р.). - Житомир : Вид. О. О. Свенюк, 2018. - С. 82 - 83. 4. Войтович І. Д. Перспективи квантових обчислень 3 використанням надпровідності / І.Д. Войтович, В.М. Корсунський // Математичні машини і системи - 2008. - № 4. - С. 23 - 56. 5. Зайцев В. Молетроника / В. Зайцев, А. Шишлова // Наука и жизнь - 2000. - № 12. - С. $64-70$.

\section{МОДЕЛИРОВАНИЕ ВОЗДЕЙСТВИЯ ШУМОВ НА КУБИТОВЫЕ И БИТОВЫЕ СИГНАЛЫ}

\author{
Игорь Анатольевич Пилькевич (д-р техн. наук, профессор) \\ Юрий Борисович Бродский (канд. техн. наук, доцент) \\ Александр Владимирович Маевский (канд. техн. наук)
}

\section{Житомирский военный институт, Житомир, Украина}

Житомирский национальный агроэкологический университет, Житомир, Украина Житомирский государственный технологический университет, Житомир, Украина

Причиной возникновения идеи квантовых вычислений является принципиальная ограниченность «классических» компьютеров решать определенный класс задач с необходимостью привлечения «экспоненциально» больших вычислительных ресурсов. Реальные квантовые системы подвержены влиянию внешней среды, что является весомым препятствием при создании квантовых компьютеров. В статье предлагается один из подходов к очениванию внешних воздействий в рамках решения проблемы сохранения достоверной информации в квантовых системах путем моделирования влияния шума на кубитовые и битовые сигналь с использованием эргодических иепей Маркова. Показано, что в ситуации постороннего влияния «шума» распределенного по экспоненциальному закону квантовая система переходит в нестабильное состояние. 
Ключевые слова: квантовые вычисления, постороннее воздействие, кубитовые сигналь, эргодические иеепи Маркова.

\title{
SIMULATION OF NOISE INFLUENCE ON QUBIT AND BIT SIGNALS
}

\author{
Igor A. Pilkevich (Doctor of Technical Sciences, Professor) \\ Yuri B. Brodsky (Candidate of Technical Sciences, Associate Professor) \\ Alexander V. Maevsky (Candidate of Technical Sciences) \\ Zhytomyr Military Institute, Zhytomyr, Ukraine \\ Zhytomyr National Agroecological University, Zhytomyr, Ukraine \\ Zhytomyr State Technological University, Zhytomyr, Ukraine
}

The reason for the quantum computing idea origin is the fundamental limitation of "classical" computers to solve a certain class of problems with a need to attract "exponentially" large computational resources. Real quantum systems are exposed to an external environment, which is a significant obstacle in the quantum computers appearance. The article proposes one of the approaches to the assessment of external influences in the framework of solving the problem of preserving reliable information in quantum systems by simulating a noise influence on qubit and bit signals using annual Markov chains. It is shown that in the situation of extraneous influence of "noise" distributed according to the exponential law, the quantum system enters an unstable state.

Keywords: quantum computations, extraneous effects, qubit signals, ergodic Markov chains.

\section{References}

1. Feynman R. Simulating physics with computers // International Journal of Theoretical Physics. - 1982.- T. 21, vp. 6-7. - P. 467-488. (Russian translation: Feynman R. Modeling of physics on computers // Quantum computer and quantum computing (volume 2) - Izhevsk: RHD, 1999. - 288 pp.). 2. Karlash G. Yu. Quantum information systems: a primary session for the specialty "Applied facial and nanomaterial" / G. Yu. Karlash. - K.: KNU im. T. Shevchenko, 2008. - 77 p. 3. Pilkevich I. A., Maevskiy O. V. Predictive analysis of the noise emission of digital signals: tezi dopovidi I Allukraine naukovo-tekhnichno conference Computer technologies: innovations, problems, solutions 19 19-20 hours 2018. - Zhytomyr: View. O. O. Uvenyuk, 2018. - p. 82 - 83. 4. Voitovich I.D. Prospects for quantum computing using superconductivity / I.D. Voitovich, V.M. Korsunsky // Mathematical Machines and Systems - 2008. №. 4. - P. 23 - 56. 5. Zaitsev V. Molletronik / V. Zaitsev, A. Shishlova // Science and Life - 2000. - №. 12. - P. 64 70 . 